\title{
Prioridades de América Latina en el diálogo Norte-Sur
}

'Iodos conoccmos la transformación que está experimentando el papel de América Latina en al economía mundial, transformación que debería ser rápida y profunda para responder a las necesidades de la etapat actual del desarrollo latinoamericano. Por su parte la economía intcrnacional también está sometida a cambios de fondo que abarcan la estructura productiva, la división internacional del trabajo, el sistema monetario y financiero y las relaciones tecnológicas entre países desarrollados y en desarrollo.

Paralclamente con estos cambios se producen diferenciaciones crecientes entre paises en desarrollo, tanto en cuitnto a sus potencialidades inmedialas cono a los problemas que cada uno de ellos debe afrontar con mayor urgencia. Sin cmbargo, es igualmente indudable que todos los países del tercer mundo mantienen entre ellos muy fucrtes denominadores comunes. Todos ellos comparten por igual cicrtos problemas y necesidades, como por ejemplo la alta dependencia de productos básicos en sus exportaciones, la necesidad de linanciamiento externo y la persistencia de problemas internos de pobreza crítica y desocupación estructural cuya solución plantca fuerte requerimientos en materia externa además de las transformaciones internas necesarias.

ks, pues, indispensable que en las políticas de cooperación entre el conjunto de países desarrollados y el conjunto de países en desarrollo se tengan en cuenta tanto los denominadores comunes a todo el Tercer Mundo como los acentos especificos que corresponden a las diferentes situaciones y matices entre países del Sur. Es perfectamente posible elaborar una política de cooperación internacional que tenga en cuenta las similitudes y las peculiaridades; pero para ello es necesario comenzar por tener explícitamente en cuenta las diferentes necesidades que surgen de distintas situaciones entre países en desarrollo, para construir una unidad que asimile la diversidad. De no hacerlo se podrán estar relegando a prioridades secundarias aspectos que son de importancia capital para algunos tipos de países en desarrollo. El hecho de no enfrentar decididamente este problema está contribuycndo a crear confusión en el diálogo internacional y a dilicultar la obtención de una unidad más profunda y auténtica del tercer mundo. 


\section{CONTRASTES DEL DESARROLLO LATINOAMERICANO}

Los grandes contrastes que caracterizan el desarrollo de muchos países latinoamericanos en la actualidad está dado por los avances o transtormaciones considerables logrados en ciertos aspectos, que coexisten con grandes retrasos o persistencia de serios problemas, en otros. Veamos algúnos ejemplos. Evidentemente no se puede desconocer el gran desarrollo de la manufactura, sobre todo de las industrias livianas, en buena parte de los países de la región. Se produce una amplia gama de bienes, algunos de ellos de requerimientos tecnológicos considerables, se satısface una alta proporción de la demanda interna de esos bienes y en muclios casos se ha logrado un grado de eficiencia muy considerable que se traduce en costos y calidades competitivos; por ello se están exportando manufacturas, aún en industrias de tecnologfa bastante avanzada couro las mecánicas.

Tampoco se puede desconocer que el desarrollo tecnológico, si bien todavía insuticiente, es ya muy significativo. No es esta la ocasión para que nos explayemos en datos y ejemplos, pero hay estudios especíticos muy interesantes de casos que muestran que liay una realidad muy concreta en el plano tecnológico ${ }^{1}$. Cuando se afirma que América Latina es una región de desarrolo tecnológico insuficiente se está diciendo una verdad a medias, pues si bien es mucho lo que falta por hacer también es cierto que existe una base de adaptación tecnológica que, debidamente ampliada, serviría para alcanzar un grado aún mayor de competitividad basado en innovación tecnológica.

También es conocido el avance importante logrado en capacitación de mano de obra y en educación. Una cuarta parte de la fuerza de trabajo se desempeña en niveles profesionales o directivos, además de los obreros calílicados; esta realidad no puede dejar de tenerse en cuenta en el planteamiento de la especialización y las relaciones externas de América Latina. No podemos ser solamente exportadores de materias primas ni tampoco de bienes producidos con ma. no de obra barata no calificada, porque ello no permitiria dar empleo adecuado a esta mano de obra de calificación media y alta. Debemos exportar bienes primarios, semimanufacturados y otros producidos por industrias tradicionales, pero también debemos producir y exportar bienes con mayores requerimientos de calificación y tecnologla.

También es de conocimiento común la gran transformación que ha experimentado la política económica en el sector externo. La

1CrPal. E] desarrollo económico y social y las relaciones externas de América Latina (E/CRPAC/1061. Add. 1, segunda parte capículo I. 
creación de sistemas de promoción de exportaciones, el mejor ma. nejo de las políticas cambiarias, la racionalización y el ajuste de la protección (que en general ha sido positiva, pero en algunos casos la ha reducido demasiado), son hechos indudables.

Junto a estas transformaciones, persisten estancamientos y problemas serios. El equivalente a una de cuatro personas que forma parte de la fuerza de trabajo está absolutamente desocupada en América Latina, Un tercio o más de la población tiene un ingreso que no le permite satisfacer sus necesidades elementales en una forma mínimamente razonable, La solución de estos problemas depende principalmente de politicas y transformaciones internas que mejoren la distribución del ingreso, superen la pobreza extrema y den mayor ocupación. Pero además, para eliminar o disminuir sustancialmente estos problemas se requiere un ritmo de crecimiento alto de la economia, mayor que el del pasado, el cual a su vez hace necesario remover el estrangulamiento externo y lograr un mejor sistema de relaciones con los paises desarrollados.

El comercio exterior latinoamericano tiene una estructura abso. lutamente asimétrica; se exportan predominantemente bienes cuya dernanda crece lentamente, cuyos precios tienen grandes fluctuaciones y que se producen con mano de obra poco calificada y mal remunerada (bienes primarios, semimanufacturados y de manufacturas livianas); los bienes más avanzados que se exportan, con ser ya significativos, no modifican el peso fundamental de los sectores anteriormente mencionados. Se importan predominantemente bienes cuya demanda crece rápidamente, que se producen con mano de obra altamente calificada y bien remunerada y cuya producción genera márgenes de utilidad bastante amplios. En el caso de los bienes primarios, América Latina exporta el doble o el triple de lo que importa; mientras tanto en industrias mecánicas y quimicas sus exportaciones representan apenas una décima parte de las impor. taciones. Esto contrasta con lo que ocurre en una economfa desarrollada madura, en la cual la estructura de las exportaciones se parece a la de las importaciones: en industrias de maquinarias no eléctrica estos paises exportan sumas parecidas o algo mayores que las que importan; lo mismo ocurre para la maquinaria eléctrica, los productos químicos, los textiles, etc.

El diferente comportamiento sistemático de exportacioneś e inportaciones de América Latína explica el persistente estrangulamiento externo, uno de los rasgos negativos más importantes de nuestra estructura economica, el que subsiste después de cuarenta años de industrialización. No digo que estemos igual que al prin. cipio del proceso de desarrollo industrial, porque la indole y la magnitud de los problemas han cambiado considerablemente, y ade- 
más se dan a un nivel de desarrollo mucho mayor que el de decenıos pasado. Pero el estrangulamiento externo sigue presentándose con gran agudeza. Pareció que habia desaparecido durante el auge del precio de los productos básicos en los años 1973 y 1974, pero lo ocurrido con posterioridad a ese periodo mostró de nuevo déficit de balanza de pagos superiores al $40 \%$ de las exportaciones; cuando esa proporción bajó, ello se debió a que se sacrificó en forma bastante drástica la tasa de crecimiento del producto, con los consiguientes efectos desfavorables sobre la ocupación y la posibilidad de atacar con éxito los problemas de la pobreza extrema.

Tenemos además un tinanciamiento externo basado predominantemente en fuente privadas, en particular bancarias, lo que plantea nuevas posibilidades en el sentıdo de que se pueden obtener créditos sin requerirse el intorme de un organismo internacional; pero al mismo tiempo se presentan problemas serios vinculados a la uependencia con respecto a bancos internacionales privados no sujetos a ningún control eíectivo oticial, y a la estructura destavorable de los vencimientos y costos del financiamiento. Muchos de los países de América Latina hall acumulado deudas externas cuyas proporciones se encuentran entre las más altas del mundo. El pago pun. tual de estas deudas, que constituye un punto básico de la política externa de los países ratinoamericanos, significa frecuentemente sacrificar el ritmo de crecimiento de las importaciones y por lo tanto de la actividad económica, salvo en la medida en que pudiera lograrse un mayor ritmo de crecimiento de las importaciones que ampliara la capacidad de pagos.

Este desarrollo caracterizado por grandes contrastes no puede dejar de reflejarse en la estrategia externa de estos palses. Voy a referirme aquí solamente a algunos temas, dejando de lado otros que son tratados con mayor profundidad por otros, como es el caso del financiamiento, de los productos básicos y de la exportación de manulacturas. Los temas a que me voy a referir están relacionados con un tema central, que es el de la división internacional del trabajo. A pesar de que la discusión internacional frecuentemente recurre a slogans, creo que el cambio en la división internacional del trabajo está dejando de ser uno de ellos para convertirse crecientemente en una realidad. No cabe duda de que esta división está cambiando, aunque no lo haga con la celeridad y frecuentemente con la dirección que se requeriría. Esta modificación es una de las causas de las preocupaciones que se perciben en los palses desarrollados acerca del avance de paises del Tercer Mundo en la exportación de bienes que hasta hace no muchos años eran exportados exclusivamente por los primeros. Este tema de la división internacional del trabajo presenta a su vez algunos aspectos a los cuales me quiero referir. 


\section{ACCESO A LOS MERCADOS Y PROTECCIONISMO}

Se dice con frecuencia de las tarifas de los países desarrollidos son bastante bajas en promedio, y que han llegado a los actuales nivelts reducidos a través de varias ruedas de negociación que las han ido disminuyendo desde niveles promedios del $50 \%$ que tenian en la postguerra, hasta un nivel algo menor al $10 \%$ que tienen en la actualidad. Esto es cierto, pero constituye una verdad a medias, porque oculta diferencias muy importantes entre los niveles de protección que los países desarrollados acuerdan a distintos biencs. Efectivamente, los tipos de bienes que exportan a estos países desarrollados los países en desarrollo, son objeto de niveles tarifarios muy superiores a ese promedio. En el caso de América Latina, una investigación hecha en CEPAL abarcando 20.000 milloncs de dólares de exportaciones anuales de la región, vale decir, una proporción alta del total, muestra que las tarilas promedio palla estos bienes de Lstados Unidos, a la Comunidad Económica Luropea y Japón, representan protecciones efcctivas que oscilan para grandes grupos de biencs entre $20 \%$ y $60 \%$ en promedio, y que para algunos casos superan el $100 \%$. En la investigación de Cili $\mathbf{X} \mathrm{L}$ se ha estimado que el efecto de este proteccionismo se traduce en una reducción anual de 2.770 millones de dólares de las exportaciones de América Latina a las tres áreas desarrollid das mencionadas. A este nivel alto de la protección de países desarrollatos se agregan algunas características desfavorables de la misma.

En primer lugar, la protección del Norte está ligada a lo que se llama "escalonamiento de las tarifas". A la materia prima no se la grava. Al artículo semiprocesado se lo grava con un nivel más alto. Al producto primario completamente claborado se lo grava aún mucho más. De modo que se desalienta de una manera muy efectiva la industrialización de las materias primas en los mismos países en desarrollo.

Además, en este momento lo más grave no está constituido por la protección tarifaria sino por la no tarifaria. Han proliferado las restricciones no arancelarias, que han crecido y se han diversificado cnormemente en los últimos tiempos y que son mucho más efectivas que las barreras tarifarias, porque con frecuencia no sólo encarecen el bien competitivo del exterior, sino que directamente impiden su entrada.

Hay que tener también en claro que este proteccionismo, que ha crecido paralelamente a una transformación profunda de la economía internacional, no debe considerarse como un hecho puramente transitorio: está aquí para quedarse, por lo menos por un tiempo relativamente largo. No puede considerarárselo como un fenómeno al que se puede hacer frente solamente mediante medi- 
das coyunturales, sino que requiere politicas que cambien la estructura de la economía mundial. Para darle una respuesta realmente de fondo se requiere avanzar en el redespliegue industrial, de modo que se transformen o reajusten las industrias de passes desarrollados que no tienen condiciones de viabilidad y que se dé lugat a una mayor patticipación de los paises en desarrollo en la producción de sectores para los cuales éstos tienen ventajas productivas claras. Es bien sabido que este proceso tropieza con la resistencia de muchos sectores económicos y sociales importantes de paíseś desarrollados, lo que retarda o impide la solución al problema del proteccionismo.

For otra parte, este mismo fenómeno no corresponde a una lista cerrada de bienes. Es decir, el proteccionismo no atecta solamente al calzado, al acero, a los alimentos procesados, a los textiles y algunos otros bienes cuyos casos son bien conocidos. La lista de bienes protegidos es abierta. Lo ocurrido en los últimos años sugiere que todo grupo de bienes en que el Sur alcanza una participación importante en el mercado internacional, se incluye automáticamente en la lista de bienes que se protegen en el Norte. Las negociaciones comerciales que están teniendo lugar en este momento en el GATT, y en particular los códigos de conducta que alli se están negociando, parecieran tender a institucionalizar el hecho de que no sea ilegal pasar un bien de la categoria de no protegido a protegido, cuando un país considere que está peligrando una parte de su industria (aunque la misma sea artificial) o que se están agravando ciertos problemas internos.

Hasta ahora, las reglas y las tendencias en la organización institucional del comercio internacional hacian de elıa una orgınización que propendía hacia la liberación. Actualmente esto se ha convertido en una organización que, sin ser demasiado pesimista, puede considerarse que tiende a institucionalizar como regla el proteccionismo que antes era excepción. Esto es lo que ocurre cuando se aplican salvaguardias o derechos compensatorios. Al mismo tiempo se pone en peligro la política de promoción de exportaciones que pueden realizar paises en desarrollo para tratar de abrirse paso en nuevos mercados con bienes que para ellos son no tradicionales.

Aparte de las barreras, de los derechos compensatorios y las salvaguardias que he mencionado, vale la pena destacar lo que eufemisticamente se llaman "restricciones voluntarias", por las cuales se le dice a un país que si no quiere que se le apliquen restricciones más fuertes, él mismo tiene que reducir sus exportaciones, lo que quiere decir que a posteriori ni siquiera puede protestar, porque formalmente las ha reducido en forma voluntaria. También están los acuerdos de regulación de mercados, otro eufemismo mo- 
derno, como el caso del acuerdo textil, que se usa para designar mecanismos que en la práctica se traducen en que la tasa de crecimiento permitida para las exportaciones de numerosos países en desarrollo, y en particular los países latinoamericanos, sea muchas veces menor a $1 \%$ anual.

He mencionado las negociaciones comerciales multilaterales de Ginebra. Se había puesto mucha esperanza en que estas negociaciones servirían para liberalizar el comercio y permitir a los países en desarrollo un acceso más pleno al mercado de países desarrollados. Se pensaba además que se establecerían normas más favorables para los países del Sur, teniendo en cuenta la desventaja transitoria inicial que corresponde a economías en proceso de desarrollo. La Declaración de Tokio daba amplios motivos para esperar el cumplimiento de estos objetivos. Lamentablemente, los resultadus obtenidos son decepcionantes. Una investigación realizada en CEPAL muestra que el incremento de exportaciones que puede esperar América Latina por las concesiones recibidas en estas negociaciones que demoraron varios años, es insignificante, pucs representa sólo 370 millones de dólares anuales, apenas una pequeña fracción de la pérdida de exportaciones producida por el proteccionismo de estos últimos años, sin contar con que, como se dijo, este proteccionismo sigue en aumento y sus consecuencias negativas crecen incesantemente.

¿Qué se puede hacer frente al proteccionismo? Hay dos formas complementarias de operar. Un camino consiste en luchar por un nuevo orden económico internacional, de modo que no sólo se detengan estas tendencias negativas que actualmente caracterizan al comercio internacional, sino que, por el contrario, las mismas se inviertan y se avance hacia un sistema de reglas más justo y más conveniente para todos los países, especialmente parid los países en desarrollo. Lsto parece por el momento muy poco realista, teniendo en cuenta las perspectivas poco favorables de la economía internacional y el hecho de que siguen acumulándose restriccioncs que acentúan los aspectos negativos del sistema. Sin embargo, evi. dentemente tanto en el Norte como en el Sur hay grupos importantes que comprenden el efecto negativo que para todos ticnen estas tendencias proteccionistas, lo que permitiria esperar que una vez que se aprenda a dar su verdadera magnitud al problema, asi como también a conciliar las soluciones que requieren los problemas de corto plazo con las necesidades de largo plazo, se pueda avanzar en forma más rápida que ahora en la creación de un nue. vo orden económico internacional. Por lo tanto, es indispensable seguir trabajando en este sentido. La reestructuración de la economía mundial debcría ser una de las consecuencias de este nucvo orden económico internacional. 
Complementariamente, mientras tanto, hay que hacer algo concreto para enfrentar la situación actual con la premura necesaria. Desde luego esta situación, con lo desfavorable que es, permite al. gunos márgenes de acción. Para ello es necesario estudiar con cuidado y realismo, caso por caso, el margen de acción disponible, como hay que hacer para aprovecharlo y para ampliarlo. Se puede lograr una diversilicación de las exportaciones, significativa a corto plazo y mucho mayor a media y largo plazos. También en el corto plazo se pueden adoptar medidas que contribuyan a desalentar estas tendencias proteccionistas de paises desarrollados. En reuniones recientes los palses de América Latina han adoptado actitudes crecientemente severas, planteando la necesidad de tomar represalias frente a medidas proteccionistas injustificadas. Los pafses latinoamericanos, según lo acordado, concertarian su acción de forma que los afectados apliquen medidas simétricas a los paises desarrollados que adopten las medidas objetadas. Es decir, si un pals desarrollado restringe las exportaciones de Anérica Latina se buscará restringir las importaciones procedentes de ese país o condicionar la participación del mismo en algún proyecto de su interés, para que no siga aplicando las medidas que desfavorezcan las ventas latinoamericanas. Evidentemente la polftica de restricción no favorece a nadie, pues en definitiva el proteccionismo de algunos palses va desatando un proceso acumulativo de restricciones $q e_{3}$ en lugar de solucionar los problemas de pagos de algún pals o grupo de paises, se traducirán en una compresión del ritmo de crecimiento del comercio y de la economla mundial. Es de esperar entonces que esta actítud más enérgica de América Latina y otros paises en desarrollo sirva para desalentar el proteccionismo y las restricciones injustificadas al comercio.

\section{LA AMBIVALENCIA DE LAS CORPORACIONES TRANSNACIONALES}

Otro tema al que me quiero referir es el de las Corporaciones transnacionales, No lo abordaré en su totalidad, sino sólo desde un ángulo que considero importante y poco explorado. Evidentemente la acción de las transnacionales tiene implicaciones en una serie de aspectos de la vida de los países, incluyendo aspectos culturales, políticos, sociales y económicos. Mi intención en este momento es solamente hacer referencia a este tema en relación al proceso al cual me estoy refiriendo, del cambio que se está producien. do en la division internacional del trabajo.

Es necesario que tenga lugar una transformación importante en las modalidades de operación de las empresas transnacionales. En un comienzo éstas llegaron a América Latina a trabajar solamente en el sector de los recursos naturales. Posteriormente comenzaron 
a producir manufacturas, pero haciéndolo exclusivamente para el mercado interno de cada país. Al mismo tiempo, su acción suponúa una actitud totalmente pasiva y dependiente de los países latinoamericanos en materia de tecnologia y distribución internacional de los bienes producidos, particularmente para el caso de las manufacturas. El grado de madurez industrial y tecnológica alcanzado por América Latina y las necesidades de la etapa actual del desarrollo de estos países, requieren un oambio muy importante en la forma de operar de estas empresas en la región. Es preciso dar lugar a un reforzamiento importante de la capacidad tecnológica latinoamericana, ampliando y reforzando muy sustancialmente los logros significativos pero pequeños alcanzados. Es necesario también proceder a reforzar las empresas nacionales o regionales latinoamericanas. Es indispensable lograr que no solamente se produzcan con participación de empresas transnacionales bienes manufacturados para los mercados internos, sino que además se exporte una parte importante de esta producción a los mercados mundiales, de modo que América Latina cambie su división internacional del trabajo y venda al exterior bienes de tecnología relativamente avanzada. Es preciso que las empresas nacionales y multinacionales latinoamericanas también exporten efectivamente y lo hagan en una situación que no dependa exclusivamente de la voluntad de empresas transnacionales. Al mismo tiempo, es neccsaria la cooperación de estas empresas para aportar a Amćrica Latina la tecnología y el conocimiento de los mercados externos de que disponen y que la región necesita. Por supuesto los países latinoamericanos y las empresas nacionales o regionales deben pagar por esta tecnología precios razonables. En síntesis, es necesario lograr una situación que pase de la dependencia a la interdependencia.

Para esto se requiere, entre otras cosas, cambiar varios aspectos importantes de la forma de operar de estas empresas transnacionales en América Latina. Algo está ya comenzando a ocurrir en la región y en el mundo; es necesario intensificar sustancialmente es. tas tendencias. Algunos países están buscando nuevas formas de contratación con las transnacionales, que sean más ventajosas que las modalidades del pasado. No voy a dar ejemplos concretos que se pueden encontrar en un trabajo reciente de CEPAL ${ }^{1}$. Pero sí voy a mencionar brevemente algunos de los tipos de nucvas modalidades que vale la pena considerar cuidadosamente.

Una de las nuevas tendencias es la de buscar arreglos de co-producción en virtud de los cuales se divide la producción de un bien entre un país desarrollado y un país en clesarrollo, con lo cual es-

${ }^{1}$ CEPAr, El Desarrollo Eeonomico y Social y las Relacionés Extemas de América Latina, Volúmen $1 \mathrm{r}$, Capftulo vir. 
te último pasa a tener un lugar en el mercado mundial para exportar una parte de esos bienes, los que generalmente corresponden a sectores nuevos, como los de industrias mecánicas y químicas, incluyendo bienes de capital. Otra modalidad similar a la anterior se refiere a los arreglos de especialización, por los cuales se distribuyen modelos en lugar de piezas. También hay ejemplos de arreglos de subcontratación del tipo de la maquila que son más conocidos; México exporta mil millones de dólares anuales mediante este tipo de arreglos. Esta última modalidad tiene similitudes con las anteriores, aunque me parece que es mucho menos favorable, en el sentido de que la industria nacional correspondien. te queda en una situación más dependiente y que esta modalidad tiene pocos efectos favorables de difusion tecnológica e industrial en el resto de la economia. En el caso de México y otros paises se está tratando de reemplazar estos arreglos de subcontratación por alguna otra modalidad más conveniente.

Otro aspecto en que se advierte una bủsqueda de mejoramiento de la capacidad negociadora de los palses anfitriones, es en el desarme del paquete de las inversiones internacionales. En lugar de que éstas provean en un solo conjunto indivisible financiamiento, tecnología y manejo de plantas, siendo al mismo tiempo dueñas exclusivas o mayoritarias de la inversión, se busca comprarles separadamente aquellos aspectos que el pas en desarrollo correspondiente necesita para cada caso en particular: adquirit la tecnologia, sin que la empresa extranjera sea dueña de la planta; aún dividir el paquete tecnológico adquiriendo en distintos origenes diferentes partes de esa tecnologia, $O$ bien haciendo arreglos que permitan al país tener acceso a la red de distribución internacional de la empresa transnacional, sin que ésta sea dueña de la planta local o controle los procesos productivos.

También se busca inducir asociación de empresas transnaciona. les con empresas nacionales o regionales. Esto no asegura el manejo nacional efectivo, aún en el caso de que exista una mayonia de capital local. Pero por lo menos permite un cierto control y un cierto conocimiento acerca de los procesos de producción y distribución que va creando la posibilidad de un manejo nacional más completo en el futuro.

Arreglos similares a algunos de los mencionados están teniendo lugar en las relaciones de empresas transnacionales con paises socialistas de Europa. Estas modalidades tienden también a aplicar. se frecuentemente en las relaciones de empresas transnacionales con otros palses desarrollados de economia de mercado. Asimismo en América Latina algunos palses han comenzado a buscat modificar los términos tradicionales de operación de estas empresas. Es. 
to está ocurriendo en la industria automotriz, en la producción de bienes de capital, en empresas químicas, etc.

¿Cuales son los elementos del pader de negociación de América Latina que permiten a la región inducir estas nuevas modalidades? Citaré aquí solamente algunos.

En primer lugar, el mercado interno latinoamericano es una realidad indiscutible debido al aumento de la población y del in. greso per cápita y el crecimiento de los sectores medios. Latino. américa posee uno de los mercados efectivos más grandes del mundo. No constituye una unidad económica sino por lo menos cuatro mercados importantes (Brasil, México, Argentina y el Grupo Andino) y algunos otros de menor tamaño. Pero evidentemente la gran magnitud de demanda efectiva actual para manufacturas explica el hecho de que, aparte de la inversión de los transnacionales en otros paises desarrollados distintos al de origen, el área del mundo en desarrollo donde la cantidad de inversión extranjera es mayor en comparación con cualquiera otra, es America Latina: sobre todo en la industria, hecho ligado al desarrollo manufacturero ya aloanzado. En la medida en que se fueran incorporando al mercado los vastos sectores de población actualmente marginados del mismo, se podria ir consolidando un mercado de más de 600 millones de personas para fin de este siglo.

Por otra parte, la región dispone de recursos naturales, muchos de ellos escasos, cuya importancia se ha puesto de manifiesto degde el aumento de los precios del petroleo.

El poder de negociación potencial bastante importante de la region ha sido usado hasta ahora en forma muy limitada. En algunos casos, si una empresa transnacional quiere entrar a producir al mercado de un pats latinoamericano, se le dice que para ello tiene que exportar por lo menos una cierta cantidad por año, o tiene que aceptar determinadas condiciones de asociación con capitales nacionales, o tiene que vender la tecnologia separada de la planta. Aunque por supuesto las empresas transnacionales no es. tản dispuestas a aceptar cualquier condición, su gran interés por el mercado y los recursos naturales latinoamericanos se traduce en que cuando la actitud del pais es firme negocian y frecuentemente aceptan condiciones sensiblemente distintas a las del pasado.

Otro elemento en juego, que por cierto es preciso manejar con cuidado, es el de las diferencias de salarios entre los paises latinoamericanos y los paises desarrollados. Con igualdad de calificación y productividad, los salarios latinoamericanos suelen ser sustancialmente más bajos que los de países desarrollados, entre otras cosas debido al menor ingreso per cápita y a las legislaciones sociales latinoamericanas menos avanzadas que las de pafses desarrolla. 
dos. Esto genera en la práctica un interés de empresas transnacionales por producir en América Latina, para ganar posibilidades de competitividad en sus ventas en el mercado internacional, mediante costos más bajos. Este atractivo es un elemento que los paíss latinoamericanos deben tener en cuenta, Sin embargo, serfa altamente perjudicial caer, en un modelo de industrialización basado en la exportación de manufacturas a expensas de salarios y condiciones de trabajo envilecidos, que no soblo impidan todo progreso social, sino que aún deterioren la distribución del ingreso, que ya es actualmente muy insatisfactoria. Por otra parte, tampoco es conveniente exportar solamente bienes producidos con mano de obra poco calificada. De todas maneras, en virtud de la distancia todayia grande que media entre el ingreso per cápita latinoamericano y el de paises desarrollados, aún dando lugar a un mejoramiento en la distribución del ingreso y en las condiciones del trabajo, el costo de la mano de obra de América Latina puede ser por un tiempo menor que el de palses desarrollados, lo que con. cede a la región una ventaja comparativa importante para la ex. portación de muchos bienes manufacturados, aún mecánicos y bienes de capital. El argumento que se escucha frecuentemente en paises desarrollados es el de que los paises en desarrollo están exportando sobre base de dumping constituido por la mano de obra barata. Este argumento olvida que mientras exista en América Latina mano de obra estructuralmente desocupada, los salarios de la región probablemente continuarán siendo más bajos que los de paises desarrollados. Precisamente para superar estos problemas de desocupación, además de las necesarias reformas internas, es indispensable dar lugar a un mayor crecimiento de las exportaciones latinoamerioanas hacia paises desarrollados, en forma que permita una mayor tasa de crecimiento que de lugar a una coupación más alta de mano de obra.

En cuanto a posibles políticas latinoamericanas que permitan un cambio en Jas formas de operar de empresas transnacionales, sin intentar de ninguna manera agotar el terna, quiero mencionar dos que se usan complementariamente: una es la via de la regla. mentación legal (como es el caso del Grupo Andino mediante la Decisión 24 y el de numerosos paises que tienen legislaciones en este sentido, como es el caso de México) y la otra es la negociación caso por caso, crecientemente usada por algunos paises como Brasil.

La reglamentación en general está destinada a fijar condiciones minimamente favorables para los parses y a cautelar ciertos objetivos e intereses nacionales. La negociación caso por caso permite discutir con cada empresa transnacional las condiciones en que va a operar, en forma que se mejore la base fijada por la reglamen. 
tación. Esta negociación caso por caso se refiere, entre otros, a algunos de los aspectos que ya han sido mencionados: acuerdos de co-producción, exportación de parte de la producción, desarme del paquete de la inversión privada y de la tecnología, asociación con capital nacional, etc. Se remarca que ambos tipos de políticas, Ia reglamentación y la negociación, lejos de ser sustitutivos son complementarios. Desde este punto de vista, el código internacional de conducta de empresas transnacionales, que constituye una forma de reglamentación acordada internacionalmente, debe ser complementado con negociaciones adecuadas en que los países latino. americanos y otros en desarrollo utilicen el peso que le acucrdan las ventajias que han sido mencionadas.

\section{LA COOPERACION ECONOMIGA REGIONAL}

Es casi un lugar común decir que la integración está en crisis. Sin cmbargo, una observación objetiva de lo que está pasando en esta materia y del papel que la cooperación regional necesita cumplir frente a la actual coyuntura internacional desfavorable, obliga a revalorarla y a asignarle un papel ciertamente más importante que el que muchos grupos intelectuales y de acción parecerían dispuestos a atribuirle.

Por primera vez en la historia, los países latinoamericanos llegaron a tener un coeficiente de exportaciones a la región que representó el $17 \%$ de sus exportaciones totales. Este coeficiente había sido del $12 \%$ en los años 50; cayó cuando se desmontaron los tratados bilaterales, llegando al $8 \%$ en los años 60 , y volvió a remontarse al $12 \%$ a principios de los años 70 . Precisamente con ocasión de la crisis mundial se remontó en un par de años, pasando de algo más de $14 \%$ a un poco más de $16 \%$; a partir de allí ha seguido subiendo lentamente. Esta es una proporción todavia limitada, pero ciertamente ya significativa. A nivel de sectores el panorama es aún más claro. En el año 1976, de las exportaciones totales de los países latinoamericanos a la zona, más de la mitad corresponde a manufacturas; en comparación con esto, en las exportaciones hacia afuera de América Latina, solamente corresponde a manufacturas menos de la cuarta parte. Es decir, que hay una estructura muy diferente en el comercio hacia la zona y hacia el resto del mundo. Aún más, tomando datos correspondientes a un grupo de países de Alalc, del total de manufacturas exportadas dentro de la zona, más de las tres cuartas partes son de industrias mecánicas y químicas, mientras que de las que van hacia afuera el $40 \%$ pertenece a estos sectores. Además, el mercado regional es muy importante en comparación con el mundial, precisamente en las industrias más avanzadas. Del total exportado de 
industrias mecánicas y químicas, el $45 \%$ va al mercado regional. Esta es una realidad que no deja de tener importancia. En buenas cuentas, el mercado regional está ayudando a desarrollar la exportación hacia afuera, precisamente en los sectores de más tras. cendencia, tanto por lo que significan en diversificación de las ex. portacionés como por su impacto tavorable en el desarrollo industrial.

A pesar de las dificultades innegables que han atravesado los procesos de integración y del estado de animo bilateralista de los palses latinoamericanos, que en cierta forma condicionan un avance más rápido de la integración formal, se estáa prołluciendo una acelerada integración real de data más reciente, que no puede desconocerse, y que se ha incrementado muy rápidamente desde que se iniciaron las dificultades para exportar hacia afuera en vinculación con la crisis mundial. Lo que ocurra de ahora en adelante dependerá de lo que suceda con las condiciones externas, de la voluntad política de los paises y del hecho de que éstos diseñen y apliquen una política clara en esta materia. Si las condiciones externas continuan siendo poco favorables, habrá una razón muy fuerte para dar gran impulso a la cooperación zonal, que depende de la voluntad de los propios paises latinoamericanos y que permititia mantener un mayor dinamismo de su crecimiento, aunque el ritmo de expansión del comercio mundial no fuera bueno. El respaldo a los mecanismos de integración formal y su flexibiliza. ción y actualización son indispensables para esto.

Quiero destacar la gran importancia de las modalidades de la cooperación informal, y la evolución muy dinámica que está teniendo lugar a este respecto, tanto por la variedad de modalida. des nuevas aplicadas como por la intensidad con que están siendo llevadas a cabo. En el trabajo de cepar ya citado, se presenta un inventario de algunas de las modalidades informales más importantes. También es evidente la necesidad de impulsar y profundizar estas modalidades. Además, un problema al que debe prestarse atención preferente es el de como hacer converger estas modalidades con los procesos formales de integración. No es conveniente que avancen separadamente, sin conexión entre si. Me parece que seria de beneficio de ambos, el hecho de que pudieran converger y de que en el marco de los procesos forinales de integración se pudieran cobijar si no todos por lo menos una buena parte de estas modalidades informales de cooperación.

Termino este punto mencionando un hecho que me parece importante en relación con el impulso a los procesos formales de integración. Es sabido que el año próximo vence el período de transición fijado para alalc por el Tratado de Montevideo. Eso obli- 
ga a negociar la prolongación de ese plazo, lo que a su vez abre la oportunidad de introducir modificaciones a este proceso para devolverle dinamismo. Es de gran importancia para América La. tina que esta oportunidad se aproveche.

\section{LAS NEGOCIACIONFS SOBRE PRODUCTOS BASICOS}

Finalmente quiero referirne al futuro inmediato en materia de neguciaciones sobre productos básicos, en especial, al P'rograma Integrado de la uncrad.

Más de las cuatro quintas partes de las cxportaciones latinoamericanias todalvía están constituidas por productos básicos, de modo que no se puede desconocer la importancia de los mismos. Aún para los países de mayor tamaño y desarrollo de la región, estos bienes representan no menos del $50 \%$ de sus exportaciones. Las negociaciones internacionales han estado orientadas fundamentalmente a la estabilización de sus precios. Se hat negociado el Programa Integrado de UNCTAD y se han hecho las consultas par.u tratar de hacer convenios sobre productos específicos.

En cuanto a las consultas relativas a los convenios sobre productos específicos, en los últimos dos años el resultado ha sido desalentador. Salvo el caso del caucho, se ha avanzado muy poco. Aparentemente uno de los problemas que han influido en estos resultados ha sido la falta de seguridad de obtener financiatmiento para las reservas estabilizadoras que deberían prever estos acucr. dos. Por ello, además del efecto sicológico que podría tener la creación del Fondo Común, este sería un elemento importante para la celebración de nuevos acuerdos. Pero evidentemente no se thata solamente de un problema financiero. Es indudable la existencia de problemas concretos y complejidades técnicas para la celebración de acuerdos. Si hubiera una voluntad política más favorable para abordar estos problemas, se podría avanzar bastante más cn este campo.

En cuanto al Fondo Común, se há llegado a acuerdo sobre las bases para su establecimiento. Es lamentable que cl monto decidido sea mucho más modesto que el originalmente previsto, por lo que surgen dudas acerca de la efectividad de su operación frente a la gran magnitud de los recursos que scrian necesarios para lograr una estabilidad razonable de los precios de un grupo de productos básicos. Es de esperar que el monto convenido sea sólo cl comienzo que conduzca en el futuro a un Fondo apropiado.

Uno de los temas respecto a los que se llegó a acuerdo en rclación con el Fondo, es el relativo al concepto de fuente o de "pool". Los países desarrollados sostenían inicialmente que era 
necesario esperar a que existiera un cierto número de acuerdos de productos que requirieran el establecimiento de reservas estabiliziauoras, y una vez que ello ocurriera se reunirian los fondos que tinanciarian esas reservas para constituir el Fondo Comun. Los paises en desarrollo sostuvieron desde el principio la necesidad de que el Fondo fuera pre-existente a los acuerdos, de modo que precisamente la disponibilidad de financiamiento alentara la firma de acuerdos y el establecimiento de reservas estabilizadoras. En esto la posición de los países desarrollados ha evolucionado hasta aceptar el principio sostenido por los paises en desarrollo.

Otro aspecto en el que ta habido una evolución, es el de la segunda ventanilla. Los paises desarrollados aceptaron que además de que el Fondo financie reservas estabitizadoras, pueda también financiar otras operaciones, por ejemplo, la transtormación del uso de los recursos naturales para evitar la sobreproducción de ciertos bienes. También en esto existió una oposicion de paises desarrollados y dudas por parte de algunos países en desarrollo. Final. mente se ha llegado a un acuerdo estableciendo esta segunda ventanilla, fijando los montos que serán atribuidos a la misma, los que serán aplicados con base en un politica que defina cuáles tipos de operaciones podrán ser objeto de este tinanciamiento.

En cuanto al tuturo, es indudable el interés que debe tener el mundo en desarrolio, $y$ en particular América Latina, por otros aspectos de la política en materia de productos básicos. Especialmente es necesario lograr una mayor participación del Sur en la economía de los productos básicos. El mayor procesamiento de los mismos en los países de origen para ser exportados con un grado de manufacturación más alto, la mayor participación de los paises en desarrollo en la distribución y comercio internacionales de estos productos, son objetivos sumamente importantes que deben perseguirse. En cuanto a procesamiento, para 17 productos básicos exportados en años recientes desde 11 países latinoamericanos a la OECD, el 74\% se exportaba como no procesados, el 10\% como semiprocesados y el $16 \%$ en forma de procesados. Es decir, las tres cuartas partes se exportan sin procesar. Ello significa que hay un amplio campo para incrementar el ingreso generado en los palses en desarrollo por concepto de venta de estos bienes.

Desde luego hay una serie de problemas que es necesario enfrentar para lograr esos objetivos. La actitud de los países desarrollados y de las empresas transnacionales, frecuentemente no es favorable para el procesamiento local o para la mayor participación de padses en desarrollo en la comercialización y transporte de productos básicos. Exíste un escalamiento de fletes marítimos que perializa el prodccto cuando se transforma procesado en lugar de transportarse en bruto. Además, las tarifas aduaneras de países desarro- 
llados están fijadas en forma que la protección efectiva aumenta muy fuertemente a medida que el producto se importa con mayor procesamiento. También la escasez de recursos de inversión y la tecnología necesaria para el procesamiento de recursos naturales, son problemas que los paises en desarrollo necesitan resolver para hacer factibic esta evolución. Sin embargo, la gran magnitud de los beneficios que pueden obtenerse con estos procesos, justifica enfrentar estos problemas con decisión.

En cuanto a comercialización, también hay cilras para algunos productos como banano, bauxita, aluminio, manganeso y té, que muestran que seis firmas o menos controlan más de la mitad del mercado mundial de cada uno de esos productos. Desde luego no se pueden sacar conclusiones fáciles en el sentido de que se pueda obtener alguna meta especifica; pero aparentemente habría campo para obtener una participación mayor de los páses en desarrollo en la comercialización, distribución y transporte de los productos básicos, y evitar que queden márgenes de comercialización oligopólicos excesivos en manos de empresas extranjeras.

Un dato significativo que muestra que vale la pena ocuparse de estos aspectos adicionales a los de estabilización de precios, lo da el hecho de que según un estudio hecho en crpal para el caso del café abarcanco tres países productores latinoamericanos y cuatro países consumidores, el $25 \%$ del precio que paga el consumidor queda en el país productor y el resto fuera. Es conocido el cstudio realizado oportunamente en la UNCTAD para el banano, según el cual menos del $15 \%$ del precio final quedaba en el país de origen y el resto fuera del país productor. Para el caso del cacao y de los cítricos, menos de un tercio queda en el país productor. Si bien estos datos no permiten sacar conclusiones detinitivas, queda de manifiesto que existe un área que vale la pena examinar con más cuidado.

No me he referido deliberadamente a los aspectos monetarios y financieros. Solamente quiero señalar que el comercio, la tecnología, la moneda y el financiamiento deben verse como aspectos estrechamente interdependientes entre sí. En la medida en que las exportaciones latinoamericanas crezcan más dinámicamente, será menor la necesidad de financiamiento externo y al mismo tiempo será más fácil pagar los servicios de la deuda, sin que ello afecle las importaciones necesarias para el desarrollo. 